Południak Natalia, Rykiel Zuzanna, Pelic Paulina, Szymańska Natalia, Drzewi Dominik, Chrzanowski Michal, Suchowicz Katarzyna, Czerw Piotr, Burakowska Justyna, Skrzek Daria, Rejman Aneta. The level of physical activity in the lifestyle of physical education students. Journal of Education, Health and Sport. 2021;11(9):761-772. eISSN 2391-8306. DOI http://dx.doi.org/10.12775/JEHS.2021.11.09.092

https://apcz.umk.pl/JEHS/article/view/JEHS.2021.11.09.092

https://zenodo.org/record/5539399

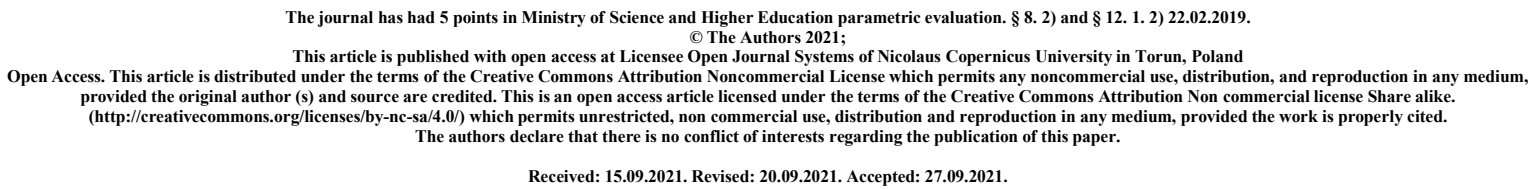

\title{
The level of physical activity in the lifestyle of physical education students
}

\author{
Natalia Poludniak (ORCID: 0000-0003-3907-9361) nataliapoludniak99@wp.pl \\ Zuzanna Rykiel (ORCID: 0000-0003-1023-5607) zuzanna.rykiel1199@gmail.com \\ Paulina Pelic (ORCID: 0000-0001-9996-7948) pinuska666@interia.pl \\ Natalia Szymańska (ORCID: 0000-0001-6691-9640) nszymanska99@gmail.com \\ Dominik Drzewi (ORCID: 0000-0002-3088-9563) drzewikus@o2.pl \\ Michal Chrzanowski (ORCID: 0000-0002-1488-2038) mchrzanowski@spoko.pl \\ Katarzyna Suchowicz (ORCID: 0000-0003-0673-1819) kaska.suchowicz@spoko.pl \\ Piotr Czerw (ORCID: 0000-0003-0193-9100) piotrekczerw@interia.pl \\ Justyna Burakowska (ORCID: 0000-0002-9428-5873) \\ justynaburakowska216@interia.pl \\ Daria Skrzek (ORCID: 0000-0001-8685-2332) daria.skrzek@onet.pl \\ Dr Aneta Rejman (ORCID: 0000-0002-0277-0856) arejman@ur.edu.pl
}

\section{Summary}

Subject: The level of physical activity in the lifestyle of physical education students

Introduction: Physical activity is defined as voluntary and spontaneous physical activity practiced during leisure time. Thanks to it, the body can function properly and develop on many levels. It plays an important role in social and physical development, as well as intellectual and emotional development. It finds its place in the fight against civilization diseases, it is also beneficial in resisting many other diseases.

Aim: The aim of the article is to assess the level of physical activity of physical education students of various specializations.

Material and methods: The research was conducted among students of physical education at the University of Rzeszów. 60 people took part in them - 38 women and 22 men aged 19-30. The respondents answered anonymously to 18 closed, single-choice questions.

Results: The majority of students are engaged in physical activity outside a college, and 65\% of it is at amateur level activity. The most common reason why respondents take up physical activity is to improve the functional fitness of the body. $58 \%$ of the respondents undertook physical activity more than 3 times a week.

Conclusions: Most of the respondents do physical activity outside of their studies. The most common reason for taking up physical activity among the respondents was the improvement of the functional fitness of the body, and the factors influencing the fact that students are physically active were to the greatest extent sports activities

Key words: physical activity; lifestyle; physical education; student. 


\section{Introduction}

Physical activity is defined as voluntary and spontaneous physical activity practiced during leisure time. Thanks to it, the body can function properly and develop on many levels. It plays an important role in social and physical development, as well as intellectual and emotional development. It finds its place in the fight against civilization diseases, it is also beneficial in resisting many other diseases. In Poland, research is carried out on academic youth in the area of pro-health and anti-health behaviors. In our country, the results are not very satisfactory. Students are reluctant to engage in sports or active recreation. They make dietary mistakes, adopt incorrect eating habits and feel stressed by exams. There are also disturbing phenomena among academic youth, such as smoking, alcohol consumption, drug addiction, problems with sexual life and body hygiene ${ }^{1}$. M. Bytniewski and J. Prymak proved that there is a relationship between physical activity and cardiovascular capacity. Physically active students are characterized by a higher cardiovascular capacity. E. Suliga conducted research that proved that male students are more active in relation to female students. Female students, on the other hand, follow more different pro-health behaviors ${ }^{2}$.

The aim of the article is to assess the level of physical activity of physical education students of various specializations. The essence is to get to know the motives for practicing activity by students, to get acquainted with the amount of time allocated to it, or with preferences regarding the sports discipline. The article presents the concept and essence of physical activity, in particular the role of physical activity in ontogenesis, the phenomenon of hypokinesia and hyperkinesia, and the aspect of physical activity in the student lifestyle. Moreover, the study of the level of physical activity among students was presented, along with the characteristics of the studied group. The article also presents an analysis of the results of this study, ending with a summary and conclusions.

Aim

The aim of the article is to assess the level of physical activity of physical education students of various specializations.

Material and methods

The research was conducted among students of physical education at the University of Rzeszów. 60 people took part in them - 38 women and 22 men. The respondents constituted a group of people aged 19-30. The research was conducted in the form of a questionnaire "The level of physical activity in the lifestyle of physical education students". The questionnaire was anonymous and consisted of 18 single-choice closed questions.

\section{Results}

According to the data, a significant group of the surveyed women $(94.7 \%)$ declared that they engage in physical activity outside of university classes. On the other hand, the remaining $5.2 \%$ of women do not engage in physical activity outside of college. All of the surveyed men undertake physical activity outside of compulsory classes at university. The recorded results showed no statistical significance (Table 1).

\footnotetext{
${ }^{1}$ M. Binkowska-Bury, M. Marć, P. Januszewicz, Health knowledge and risky behaviors in the environment of academic youth, General Medicine and Health Sciences, 2010, s. 100-113.

$2 \mathrm{~J}$. Palacz, Health behaviors of students in the light of selected conditions, General Medicine and Health Sciences, 2014, s.301-306.
} 
Table 1. Students willing to take up physical activity outside of their classes at the university.

\begin{tabular}{|l|l|l|l|l|l|}
\hline \multirow{2}{*}{ Results } & \multicolumn{2}{|l|}{ Women } & \multicolumn{2}{l|}{ Men } & \multirow{2}{*}{ p } \\
\cline { 2 - 5 } & $\mathbf{N}$ & $\mathbf{\%}$ & $\mathbf{N}$ & $\mathbf{\%}$ & \multirow{3}{*}{0,274} \\
\cline { 1 - 5 } Yes & 36 & 94,7 & 22 & 100 & \\
\hline No & 2 & 5,2 & 0 & 0 & \\
\hline Sum & 38 & 100 & 22 & 100 & \\
\hline
\end{tabular}

The analysis shows that $52.6 \%$ of women and $68.1 \%$ of men undertake physical activity more than 3 times a week. $39.4 \%$ of women and $27.2 \%$ of men undertake physical activity 2-3 times a week. $5.2 \%$ of women and $4.5 \%$ of men do physical activity once a week. Only $2.6 \%$ of women do not undertake physical activity. There was no one among men who would not be physically active. At the same time, the recorded results did not show statistical significance (Table 2).

Table 2 . The frequency of undertaking physical activity by students.

\begin{tabular}{|l|l|l|l|l|l|}
\hline \multirow{2}{*}{ Results } & \multicolumn{2}{l|}{ Women } & Men & \multirow{2}{*}{ p } \\
\cline { 2 - 5 } & $\mathbf{N}$ & $\mathbf{\%}$ & $\mathbf{N}$ & $\mathbf{\%}$ & \\
\hline 2-3 times a week & 15 & 39,4 & 6 & 27,2 & \\
\hline Once a week & 2 & 5,2 & 1 & 4,5 & \multirow{2}{*}{0,623} \\
\hline More than 3 times a week & 20 & 52,6 & 15 & 68,1 & \\
\cline { 1 - 5 } Not taking at all & 1 & 2,6 & 0 & 0 & \\
\hline Sum & 38 & 100 & 22 & 100 & \\
\hline
\end{tabular}

Analyzing the data in Table 3 regarding the time taken by students to take up physical activity, it can be noticed that $47.3 \%$ of women undertake physical activity in the $30-60$ minutes range, $28.9 \%$ of women exercise more than 60 minutes, and $21.05 \%$ of physical activity takes up to 30 minutes, and $2.6 \%$ are not physically active. Among men, $77.2 \%$ undertake physical activity for more than 60 minutes, $18.1 \%$ within 30-60 minutes of exercise, and $4.5 \%$ train for 30 minutes. The recorded results showed statistical significance.

Table 3. Time of physical activity undertaken by students.

\begin{tabular}{|c|c|c|c|c|c|}
\hline \multirow{2}{*}{ Results } & \multicolumn{2}{|c|}{ Women } & \multicolumn{2}{|c|}{ Men } & $\mathbf{p}$ \\
\hline & $\mathbf{N}$ & $\%$ & $\mathbf{N}$ & $\%$ & \multirow{6}{*}{$0,005^{*}$} \\
\hline up 30 minutes & 8 & 21,05 & 1 & 4,5 & \\
\hline 30-60 minutes & 18 & 47,3 & 4 & 18,1 & \\
\hline Above 60 minutes & 11 & 28,9 & 17 & 77,2 & \\
\hline I'm not physically active & 1 & 2,6 & 0 & 0 & \\
\hline Sum & 38 & 100 & 22 & 100 & \\
\hline
\end{tabular}

*- statistical significance at the level $\alpha=0.05$

The above data indicate that the most frequently undertaken physical activity among women is running (44.7\%). Cycling and strength training were chosen by $13.1 \%$ of women. Among men, the most frequently undertaken physical activity is strength training, which was chosen by $45.4 \%$ of students. Running and cycling are most frequently undertaken by $13.6 \%$ of students. The recorded results showed statistical significance (Table 4).

Table 4. Physical activity most frequently undertaken by students.

\begin{tabular}{|l|l|l|l|}
\hline Results & Women & Men & p \\
\hline
\end{tabular}




\begin{tabular}{|c|c|c|c|c|c|}
\hline & $\mathbf{N}$ & $\%$ & $\mathbf{N}$ & $\%$ & \multirow{7}{*}{$0,001 *$} \\
\hline Running & 17 & 44,7 & 3 & 13,6 & \\
\hline Cycling & 5 & 13,1 & 3 & 13,6 & \\
\hline Training in the gym & 5 & 13,1 & 10 & 45,4 & \\
\hline None & 1 & 2,6 & 0 & 0 & \\
\hline Other & 10 & 26,3 & 6 & 27,2 & \\
\hline Sum & 38 & 100 & 22 & 100 & \\
\hline
\end{tabular}

*- statistical significance at the level $\alpha=0.05$

Based on the figures in Table 5, it can be seen that the most common reason for undertaking physical activity by $60.5 \%$ of female students and $54.5 \%$ of students is to improve the functional fitness of the body. Losing excess body weight is the motive for undertaking physical activity for $21.05 \%$ of women and $13.6 \%$ of men. $5.2 \%$ of women and $9.09 \%$ of men engage in physical activity due to the doctor's recommendations. The least popular were such reasons as: for pleasure or because of the will to break own records, improvement of strength and body shape. The recorded results did not show statistical significance (Table 5).

Table 5. Motives for undertaking physical activity by students

\begin{tabular}{|c|c|c|c|c|c|}
\hline \multirow{2}{*}{ Results } & \multicolumn{2}{|c|}{ Women } & \multicolumn{2}{|c|}{ Men } & $\mathbf{p}$ \\
\hline & $\mathbf{N}$ & $\%$ & $\mathbf{N}$ & $\%$ & \multirow{6}{*}{0,086} \\
\hline Improving the functional efficiency of the body & 23 & 60,5 & 12 & 54,5 & \\
\hline Getting rid of excess body weight & 8 & 21,05 & 3 & 13,6 & \\
\hline Doctor's orders & 2 & 5,2 & 2 & 9,09 & \\
\hline Other & 5 & 13,1 & 5 & 22,7 & \\
\hline Sum & 38 & 100 & 22 & 100 & \\
\hline
\end{tabular}

According to the data, $55.2 \%$ of women and $59.09 \%$ of men assess their own level of physical activity at an average level. $34.2 \%$ of women and $40.9 \%$ of men are considered to be highly physically active. $10.5 \%$ of women declare a low level of physical activity. The recorded results showed no statistical significance (Table 6).

Table 6. Subjective assessment of one's own level of physical activity.

\begin{tabular}{|l|l|l|l|l|l|}
\hline \multirow{2}{*}{ Results } & \multicolumn{2}{|l|}{ Women } & \multicolumn{2}{l|}{ Men } & \multirow{2}{*}{ p } \\
\cline { 2 - 6 } & $\mathbf{N}$ & $\mathbf{\%}$ & $\mathbf{N}$ & $\mathbf{\%}$ & \\
\cline { 2 - 6 } It is at a high level & 13 & 34,2 & 9 & 40,9 & \multirow{2}{*}{0,112} \\
\hline It is at an average level & 21 & 55,2 & 13 & 59,09 & \\
\cline { 1 - 5 } It is at a low level & 4 & 10,5 & 0 & 0 & \\
\hline Sum & 38 & 100 & 22 & 100 & \\
\hline
\end{tabular}


The analysis shows that $52.6 \%$ of women and $68.1 \%$ of men are most likely to exercise outdoors (bicycle paths, parks, green areas, etc.)., $7 \%$ of women and $31.8 \%$ of men $2.6 \%$ of the surveyed women did not undertake physical effort, and the recorded results did not show statistical significance (Table 7).

Table 7. Determining the nature of the place where physical effort is most willingly undertaken.

\begin{tabular}{|c|c|c|c|c|c|}
\hline \multirow{2}{*}{ Results } & \multicolumn{2}{|c|}{ Women } & \multicolumn{2}{|c|}{ Men } & $\mathbf{p}$ \\
\hline & $\mathbf{N}$ & $\%$ & $\mathbf{N}$ & $\%$ & \multirow{5}{*}{0,420} \\
\hline Indoor (closed rooms, gyms, training rooms, etc.) & 17 & 44,7 & 7 & 31,8 & \\
\hline Outside (bike paths, parks, green spaces, etc.) & 20 & 52,6 & 15 & 68,1 & \\
\hline Do not take & 1 & 2,6 & 0 & 0 & \\
\hline Sum & 38 & 100 & 22 & 100 & \\
\hline
\end{tabular}

As the table shows, the most common motive for undertaking physical activity among women is keeping fit (47.3\%). 26.3\% of women engage in physical activity to lose unnecessary kilograms, $23.6 \%$ engage in physical activity to achieve sports goals, and $2.6 \%$ of women do not engage in physical activity. Among men, half of them undertake physical activity to achieve their sports goals. $36.3 \%$ of men choose the motive of maintaining good condition, while $13.6 \%$ of students engage in physical activity in order to lose unnecessary kilograms. The recorded results showed no statistical significance (Table 8).

Table 8 . Determination of the motives for undertaking physical activity.

\begin{tabular}{|c|c|c|c|c|c|}
\hline \multirow{2}{*}{ Results } & \multicolumn{2}{|c|}{ Women } & \multicolumn{2}{|c|}{ Men } & $\mathbf{p}$ \\
\hline & $\mathbf{N}$ & $\%$ & $\mathbf{N}$ & $\%$ & \multirow{6}{*}{0,180} \\
\hline Keeping in good shape & 18 & 47,3 & 8 & 36,3 & \\
\hline Losing unnecessary kilos & 10 & 26,3 & 3 & 13,6 & \\
\hline Achieving sports goals & 9 & 23,6 & 11 & 50 & \\
\hline Do not take up physical activity & 1 & 2,6 & 0 & 0 & \\
\hline Sum & 38 & 100 & 22 & 100 & \\
\hline
\end{tabular}

The fact that the respondents are physically active was influenced to the greatest extent by sports activities. The family influenced physical activity in $23.6 \%$ of women and $9.09 \%$ of men, while friends influenced $13.1 \%$ of the surveyed women and $9.09 \%$ of men. Another form of motivation to physical activity was chosen by $5.2 \%$ of women and $13.6 \%$ of men. The recorded results did not show statistical significance (Table 9).

Table 9. What influenced the fact that a given person is physically active.

\begin{tabular}{|l|l|l|l|l|l|}
\hline \multirow{2}{*}{ Results } & Women & Men & p \\
\cline { 2 - 6 } & $\mathbf{N}$ & $\mathbf{\%}$ & $\mathbf{N}$ & $\%$ & \\
\hline Family & 9 & 23,6 & 2 & 9,09 & \\
\hline Sports & 21 & 55,2 & 15 & 68,1 & \multirow{2}{*}{0,058} \\
\hline Friends & 5 & 13,1 & 2 & 9,09 \\
\hline I am not physically active & 1 & 2,6 & 0 & 0 & \\
\hline Other & 2 & 5,2 & 3 & 13,6 & \\
\hline Sum & 38 & 100 & 22 & 100 & \\
\hline
\end{tabular}


Based on the figures in Table 10. It can be noticed that the most frequently experienced emotions while exercising in $63.1 \%$ of women and $50 \%$ of men are joy and satisfaction. $34.2 \%$ of women and $22.7 \%$ of men experience peace and relaxation, while $2.6 \%$ of women and $13.6 \%$ of men experience tension and stress during physical activity. $13.6 \%$ of men experience different feelings. The recorded results showed statistical significance

Table 10. Emotions experienced during physical activity.

\begin{tabular}{|l|l|l|l|l|l|}
\hline \multirow{2}{*}{ Results } & \multicolumn{3}{|l|}{ Women } & Men & p \\
\cline { 2 - 6 } Calm and relaxation & $\mathbf{N}$ & $\mathbf{\%}$ & $\mathbf{N}$ & $\mathbf{\%}$ & \\
\cline { 1 - 6 } Tension and stress & 13 & 34,2 & 5 & 22,7 & \\
\cline { 1 - 5 } Joy and satisfaction & 1 & 2,6 & 3 & 13,6 & \multirow{2}{*}{$0,033^{*}$} \\
\cline { 1 - 5 } Other & 24 & 63,1 & 11 & 50 & \\
\cline { 1 - 3 } Sum & 0 & 0 & 3 & 13,6 & \\
\hline
\end{tabular}

*- statistical significance at the level $\alpha=0.05$

According to the data, most of the respondents indicated that they feel better after the activity they did than before. $97.3 \%$ of women feel better after being physically active. In men, all unanimously answered that they felt better after practicing physical activity than before starting it. At the same time, the recorded results did not show statistical significance (Table $11)$.

Table 11. Are the feelings after physical activity better than before doing it?

\begin{tabular}{|l|l|l|l|l|l|}
\hline \multirow{2}{*}{ Results } & \multicolumn{2}{|l|}{ Women } & Men & p \\
\cline { 2 - 5 } & N & \% & N & \% & \multirow{2}{*}{0,443} \\
\cline { 1 - 4 } Yes & 37 & 97,3 & 22 & 100 & \\
\cline { 1 - 4 } & 1 & 2,6 & 0 & 0 & \\
\hline Sum & 38 & 100 & 22 & 100 & \\
\hline
\end{tabular}

The analysis shows that $50 \%$ of women and $54.5 \%$ of men prefer to engage in physical activity in company. $50 \%$ of women and $18.1 \%$ of men prefer to engage in physical activity alone. For $27.2 \%$ of men, it does not matter. The recorded results showed statistical significance (Table 12).

Table 12. Preferring to engage in physical activity alone or in company.

\begin{tabular}{|l|l|l|l|l|l|}
\hline \multirow{2}{*}{ Results } & \multicolumn{2}{l|}{ Women } & Men & p \\
\cline { 2 - 5 } & $\mathbf{N}$ & $\mathbf{\%}$ & $\mathbf{N}$ & $\mathbf{\%}$ & \\
\hline Alone & 19 & 50 & 4 & 18,1 & \\
\cline { 1 - 5 } In the company & 19 & 50 & 12 & 54,5 & \multirow{2}{*}{$0,001^{*}$} \\
\cline { 1 - 5 } Whatever & 0 & 0 & 6 & 27,2 & \\
\cline { 1 - 4 } Sum & 38 & 100 & 22 & 100 & \\
\hline
\end{tabular}

$*_{\text {- } \text { statistical significance at the level } \alpha=0.05}$

According to the data, the greatest number of respondents, $65 \%$ declared that they engage in physical activity at an amateur level. About 35\% of all respondents stated that they engage in physical activity at the professional level. Among women, practicing physical activity at an amateur level dominated, approximately $73.6 \%$ of all women. On the other hand, 
among men, practicing physical activity at the amateur level $(50 \%)$ and at the professional level $(50 \%)$ was on an equal level. At the same time, the recorded results did not show statistical significance (Table 13).

Table 13. The level of practicing physical activity

\begin{tabular}{|l|l|l|l|l|l|}
\hline \multirow{2}{*}{ Results } & \multicolumn{2}{|l|}{ Women } & Men & \multirow{2}{*}{ p } \\
\cline { 2 - 5 } & $\mathbf{N}$ & $\mathbf{\%}$ & $\mathbf{N}$ & $\mathbf{\%}$ & \\
\cline { 1 - 5 } On a professional level & 10 & 26,3 & 11 & 50 & \multirow{2}{*}{0,064} \\
\cline { 1 - 5 } At the amateur level & 28 & 73,6 & 11 & 50 & \\
\hline Sum & 38 & 100 & 22 & 100 & \\
\hline
\end{tabular}

The analysis shows that the majority, i.e., $58.3 \%$ of the respondents declared that they sometimes participate in sports competitions or events. About $25 \%$ of the total said that they often take part in sports competitions or events. In both women $(55.2 \%)$ and men $(63.3 \%)$, the most frequently indicated answer was taking part in sports competitions sometimes. $23.6 \%$ of women and $27.2 \%$ of men often take part in competitions / sporting events of various types, while $21.05 \%$ of women and $9.09 \%$ of men have never participated. The recorded results did not show statistical significance (Table 14).

Table 14. Declared participation in sports competitions / events of various nature.

\begin{tabular}{|l|l|l|l|l|l|}
\hline \multirow{2}{*}{ Results } & \multicolumn{2}{|l|}{ Women } & Men & p \\
\cline { 2 - 5 } & $\mathbf{N}$ & $\mathbf{\%}$ & $\mathbf{N}$ & $\mathbf{\%}$ & \\
\cline { 1 - 5 } Often & 9 & 23,6 & 6 & 27,2 & \multirow{3}{*}{0,488} \\
\cline { 1 - 3 } & 21 & 55,2 & 14 & 63,3 & \\
\cline { 1 - 4 } Sever & 8 & 21,05 & 2 & 9,09 & \\
\hline
\end{tabular}

Analyzing the data in Table 15, it can be seen that the problem of fast fatigue when practicing physical activity among women was $47.3 \%$ of them. The inability to select and correctly perform the exercises is a problem for $31.5 \%$ of women. On the other hand, in men, the most common answer was no problems (36.3\%). The inability to choose and perform the exercises correctly was shown by $22.7 \%$ of men, and quick fatigue is a problem for $9.09 \%$ of men. The recorded results showed statistical significance (Table 15).

Table 15. Problems encountered while practicing physical activity.

\begin{tabular}{|c|c|c|c|c|c|}
\hline \multirow{2}{*}{ Results } & \multicolumn{2}{|c|}{ Women } & \multicolumn{2}{|c|}{ Men } & \multirow[t]{3}{*}{$\mathbf{p}$} \\
\hline & $\mathbf{N}$ & $\%$ & $\mathbf{N}$ & $\%$ & \\
\hline I get tired quickly & 18 & 47,3 & 2 & 9,09 & \\
\hline I cannot choose and perform the exercises correctly & 12 & 31,5 & 5 & 22,7 & \\
\hline Another & 8 & 21,05 & 15 & 68,1 & \\
\hline Sum & 38 & 100 & 22 & 100 & \\
\hline
\end{tabular}

*- statistical significance at the level $\alpha=0.05$

According to the data, the majority of respondents, about $72 \%$ agreed with the statement that "sport is health". About $13 \%$ of all respondents felt that they had no opinion on 
this matter. Among women (76.3\%) and men (63.6\%), the most frequently chosen answer was "I agree". The recorded results did not show statistical significance (Table 16).

Table 16. Opinions on the statement that "sport is health".

\begin{tabular}{|l|l|l|l|l|l|}
\hline \multirow{2}{*}{ Results } & \multicolumn{2}{|l|}{ Women } & Men & p \\
\cline { 2 - 5 } & $\mathbf{N}$ & $\mathbf{\%}$ & $\mathbf{N}$ & $\mathbf{\%}$ & \\
\cline { 1 - 5 } I agree & 29 & 76,3 & 14 & 63,6 & \multirow{2}{*}{0,100} \\
\cline { 1 - 5 } I do not agree & 2 & 5,2 & 1 & 4,5 & \\
\cline { 1 - 5 } I have no opinion & 5 & 13,1 & 3 & 13,6 & \\
\cline { 1 - 5 } Another & 2 & 5,2 & 4 & 18,1 & \\
\hline
\end{tabular}

Analyzing what physical activity is related to, $44.7 \%$ of women and $50 \%$ of men believe that physical activity is related to better health, better well-being and keeping a slim figure. $28.9 \%$ of women and $27.2 \%$ of men show that physical activity is associated with better health. $10.5 \%$ of women and $18.1 \%$ of men indicated better well-being. Maintaining a slim figure is considered a relationship with physical activity by $15.7 \%$ of women and $4.5 \%$ of men. The recorded results did not show statistical significance (Table 17).

Table 17. What is the relationship with physical activity?

\begin{tabular}{|c|c|c|c|c|c|}
\hline \multirow{2}{*}{ Results } & \multicolumn{2}{|c|}{ Women } & \multicolumn{2}{|c|}{ Men } & $\mathbf{p}$ \\
\hline & $\mathbf{N}$ & $\%$ & $\mathbf{N}$ & $\%$ & \multirow{6}{*}{0,528} \\
\hline Better health & 11 & 28,9 & 6 & 27,2 & \\
\hline Better mood & 4 & 10,5 & 4 & 18,1 & \\
\hline Maintaining a slim figure & 6 & 15,7 & 1 & 4,5 & \\
\hline All of the above & 17 & 44,7 & 11 & 50 & \\
\hline Sum & 38 & 100 & 22 & 100 & \\
\hline
\end{tabular}

All respondents would encourage people from their surroundings to undertake any physical activity. This response was obtained by both female and male representatives of $100 \%$. The recorded results showed no statistical significance (Table 18)

Table 18. Encouraging people from their surroundings to undertake any physical activity.

\begin{tabular}{|l|l|l|l|l|l|}
\hline \multirow{2}{*}{ Results } & \multicolumn{2}{|l|}{ Women } & Men & \multirow{2}{*}{ p } \\
\cline { 2 - 6 } & $\mathbf{N}$ & $\mathbf{\%}$ & $\mathbf{N}$ & $\mathbf{\%}$ & \\
\cline { 1 - 5 } Yes & 38 & 100 & 22 & 100 & \multirow{2}{*}{$0,001^{*}$} \\
\cline { 1 - 5 } No & 0 & 0 & 0 & 0 & \\
\cline { 1 - 4 } & 38 & 100 & 22 & 100 & \\
\hline
\end{tabular}

* - statistical significance at the level $\alpha=0.05$

Discussion

This work concerned the assessment of the level of physical activity in the lifestyle of physical education students. Own work was aimed at determining which sport discipline most often chosen by students. The prepared analysis of the results showed that the respondents most often practiced sports outdoors, mainly on bicycle paths, but also in green areas or parks. The most popular discipline is running (31.7\%). Gym training (25\%), cycling (15\%) and 
roller skating (5\%) are very famous among the respondents. Research shows that respondents develop physically correctly. However, only $1.7 \%$ of students do not perform any physical activity, which results in developmental disorders, various diseases (including civilization) and problems with maintaining a healthy body weight. There are many studies describing the subject of sports disciplines practiced by academic youth. Mirkiewicz's research showed that $38 \%$ of the respondents engage in recreational sport. The most popular among females was running (35\%). In turn, among men it was cycling 56\% ${ }^{3}$. Analyzing Mirkiewicz's results with his own research, it can be concluded that running is the most popular discipline practiced by the respondents, followed by cycling. Running is dominant mainly among women.

Rasińska's research has shown that the most common forms of movement chosen by respondents are cycling, swimming, walking, gym classes and dancing. Comparing the forms of activity of academic youth with the data from the Central Statistical Office of Poland, we are able to conclude that some data concerning the choices of forms of activity are at a higher level, e.g., dancing. Volleyball and swimming were at an approximate level. Football, athletics, table tennis and gymnastics were respectively less popular ${ }^{4}$. When analyzing Rasińska's results with her own research, we can find some conclusions - the most frequently undertaken physical activity among students is cycling.

When answering the question about the reasons for taking up physical activity by students, the most common answer among the respondents was the improvement of the body's efficiency or also getting rid of excess body weight. The doctor's recommendations were also important. Research conducted by Sochocka and Wojtyłko appears in many publications concerning taking up physical activity among students. When analyzing the results of Sochocka and Wojtyłko with their own research, it can be concluded that they differ. Own research shows that the main reason for taking up physical activity was to improve the functional efficiency of the body. On the other hand, research by Sochocka and Wojtyłko cites mental and physical well-being as the main reason ${ }^{5}$.

The research of Kościuszuk et al. Showed that the main reason for practicing physical activity was to maintain good physical condition ${ }^{6}$.

Thus, the reason for undertaking physical activity presented in this paper differs from the one that was most popular in the research by Kościuszuk et al.

According to other studies, by Gomołysek and Lowiński, women in the study engage in physical activity due to health aspects. A large proportion of the respondents are physically active due to their visual qualities (achieving a dream figure). The results of men are very similar to the results of women. The students emphasized that the most important reason why they take up physical activity is health (37.02\%) and improvement of physical fitness ${ }^{7}$. When analyzing the research of Gomołysek and Lowiński with his own research, differences can be noticed. In this study, both men and women are physically active due to the improvement of the body's functional capacity. On the other hand, research by Gomołysek and Łowiński emphasizes practicing physical activity most often due to health aspects.

As for the factors influencing being active by students, these were most often sports activities $(60 \%)$. The family $(18.3 \%)$ played an important role in promoting physicality.

\footnotetext{
${ }^{3}$ R. Pawłowski, The declared and actual participation of students in physical recreation, Scientific Review of Physical Culture of the University of Rzeszów, 2003, s. 165-175.

${ }^{4}$ R. Rasińska, Tourism and recreation and the lifestyle of students of Poznan universities, Scientific Papers of the WSB Banking University in Poznań, 2015, s. 121-132.

${ }^{5}$ L. Sochocka, A. Wojtyłko, Physical activity of students of full-time medical and non-medical faculties, Environmental Medicine -Environmental Medicine, 2013, s. 53-58.

${ }^{6}$ J. Kościuczuk, E. Krajewska-Kułak, B. Okurowska-Zawada, Physical activity of students of physiotherapy and dietetics, General Medicine and Health Sciences, 2016, s. 51-58.

${ }^{7}$ A. Gomołysek, T. Łowiński, Preferred forms of physical activity of students in their free time depending on the season, Yearbook of Lubuski, 2018, s. 225-239.
} 
Physically active family members encourage activity and have a huge impact on later life. The third answer was the influence of acquaintances, friends (11.7\%). There are many items related to the subject of active leisure by students, but it was not possible to find one that would describe the issue related to the research question. In the future, it would be worth using such teaching measures that will show what directly affects children and adolescents.

As you know, each person has a different character, which is why we distinguish different types of motivation. It is not proven that one type of motivation must be assigned to one person. The point of view and current trends have a significant impact on the practice of physical activity. Research conducted by Sochocka and co-authors on tourism and recreation students showed that most respondents undertake physical activity in their free time. More than half of the respondents most often make an effort with friends. The most common are aerobics fitness, swimming, dancing, cycling / inline skating, and gym exercises. Of the respondents, $37 \%$ spend their free time outdoors, $63 \%$ at home and in sports facilities ${ }^{8}$. When analyzing the results of Sochocka's research with her own research, it can be concluded that they show similarity. Both in this work and in Sochocka's research, it is noted that students undertake physical activity in their free time. Cycling is the most popular sport.

It is known that physical activity has a positive effect on human health. Pro-health behavior plays a key role in promoting health, as well as building a healthier future. The aim of the research was to analyze physical activity and the motives for undertaking it by the above-mentioned group of students. Most, as many as $79.5 \%$ of the respondents described themselves as a physically active person. The most popular forms of physical activity were cycling, walking the dog, team games, group activities and swimming. Most of the respondents, when practicing a given type of physical activity, follow their free time and preferences. For less than half of the students it is a form of spending free time ${ }^{9}$. The results of the research by Sochocka and Wojtyłko as well as their own research show a similarity in the manifestation of activities among the studied subjects.

Physical activity reduces or prevents arising posture defects ${ }^{10}$. In this study, the research showed that most of the respondents practice exercise more than 3 times a week. On the other hand, a slightly smaller proportion of respondents prefer to engage in physical activity 2-3 times a week and only once a week. Research shows that the duration of a single physical activity, according to the majority of respondents, is over 60 minutes. In the following, we can distinguish answers such as: 30-60 minutes or up to 30 minutes. Research by Szczepanowska et al. showed that the majority of respondents practice physical activity several days a week. Moreover, it can be concluded from the research that women spend their time on physical activity usually less than once a week ${ }^{11}$.

Professionalism was already present in sports in the era of the ancient Greek Games ${ }^{12}$. The research carried out in this study shows that most of the respondents $(65 \%)$ practice amateur sports. On the other hand, some practice sport professionally. About $58 \%$ of the respondents indicated that they sometimes take part in sports events. On the other hand, 25\% of the respondents stated that they regularly practice participating in the above-mentioned event.

\footnotetext{
${ }^{8}$ L. Sochocka, A. Wojtyłko, Physical activity of students of full-time medical and non-medical faculties, Environmental Medicine -Environmental Medicine, 2013, s. 53-58.

${ }^{9}$ L. Sochocka, A. Wojtyłko, Physical activity of students of full-time medical and non-medical faculties, Environmental Medicine -Environmental Medicine, 2013, s. 53-58.

${ }^{10}$ M. Wojtków, K. Korcz, S. Szotek, Influence of sport shooting on shaping the body posture, XIII Scientific Conference Majówka Młodych Biomechaników im. prof. Dagmara Tejszerska, 2016, s. 133-134.

${ }^{11}$ E. Szczepanowska, L. Pławińska, T. Sarzal, Promotion of health in various forms of tourism and recreation among students of the University of Szczecin, Motor Activity of People of Different Ages, 2014, s.31-41.

${ }^{12}$ M. Lenartowicz, The specificity of the profession of an athlete and a sports career, Humanities Studies, 2009, s. $73-84$
} 
In the conducted research, the majority of respondents believe that they feel better after doing activity than before doing it, approximately $97 \%$. On the other hand, all men feel better after being physically active than before starting it. Most of the respondents believe that movement is most often associated with better health, well-being, or keeping a slim figure. Pawłowski's research confirmed that the respondents (84\%) enjoy doing exercises, but if they were not obligatory, only $2 / 3$ of the respondents would voluntarily attend them ${ }^{13}$. When analyzing the results of Pawłowski's research with his own research, one can notice a similarity in terms of positive feelings after physical activity.

Results

Based on the research, the following conclusions were made:

1. The vast majority of people engage in physical activity outside of the university classes.

2 . The most frequently chosen activity by women is running, while among men it is strength training.

3. The main reason for taking up physical activity by the respondents is to improve the functional efficiency of the body.

4. The respondents evaluate their own level of physical activity at an average level.

5. Most students think that they feel much better after being physically active.

6. Most of the respondents agreed with the statement that "sport is health".

7. All respondents would encourage people from their surroundings to undertake any physical activity.

8. Most women believe that the problem when exercising is quick fatigue and inappropriate exercise. It is recommended to consult an experienced trainer.

9. In the majority of respondents, joy and satisfaction are the most frequently felt emotions during physical activity.

Literature

1. Binkowska-Bury M, Marć M, Januszewicz P. Health knowledge and risky behaviors in the environment of academic youth. General Medicine and Health Sciences. 2010;16(1):100-113.

2. Palacz J. Health behaviors of students in the light of selected conditions. General Medicine and Health Sciences. 2014;20(3):301-306.

3. Pawłowski R. The declared and actual participation of students in physical recreation. Scientific Review of Physical Culture of the University of Rzeszów. 2003;1-2:165175.

4. Rasińska R. Tourism and recreation and the lifestyle of students of Poznań universities. Scientific Papers of the WSB Banking University in Poznań. 2015;63(6):121-132.

5. Sochocka L, Wojtyłko A. Physical activity of students of full-time medical and nonmedical faculties. Environmental Medicine -Environmental Medicine. 2013;16(2):5358.

6. Kościuczuk J, Krajewska-Kułak E, Okurowska-Zawada B. Physical activity of students of physiotherapy and dietetics. General Medicine and Health Sciences. 2016;22(1):51-58.

7. Gomołysek A, Łowiński T. Preferred forms of physical activity of students in their free time depending on the season. Yearbook of Lubuski. 2018;44(2a):225-239.

${ }^{13}$ R. Pawłowski, Positive feelings of students from physical education classes as an indispensable factor of voluntary physical activity in their free time, The School of Physical Education and Sport at the Świętokrzyska Academy in Kielce, 2007, s. 76-79. 
8. Sochocka L, Wojtyłko A. Physical activity of students of full-time medical and nonmedical faculties. Environmental Medicine -Environmental Medicine. 2013;16(2):5358.

9. Sochocka L, Wojtyłko A. Physical activity of students of full-time medical and nonmedical faculties. Environmental Medicine -Environmental Medicine. 2013;16(2):5358.

10. Wojtków M, Korcz K, Szotek S. Influence of sport shooting on shaping the body posture. XIII Scientific Conference Majówka Młodych Biomechaników im. prof. Dagmara Tejszerska. 2016:133-134.

11. Szczepanowska E, Pławińska, L, Sarzala T. Promotion of health in various forms of tourism and recreation among students of the University of Szczecin. Motor Activity of People of Different Ages. 2014;1:31-41.

12. Lenartowicz M. The specificity of the profession of an athlete and a sports career. Humanities Studies. 2009;9:73-84.

13. Pawłowski R. Positive feelings of students from physical education classes as an indispensable factor of voluntary physical activity in their free time. The School of Physical Education and Sport at the Świętokrzyska Academy in Kielce. 2007; Vol. LXII, SUPPL. XVIII, N. 6, 589:76-79. 